\title{
Designing Heritage-Sensitive IP and Marketing Strategies for ICH-Based Creative Economy
}

\author{
Ananya BHATTACHARYA ${ }^{1}$, Madhura DUTTA ${ }^{2}$, Charlotte WAELDE ${ }^{3}$ \\ 1 banglanatak dot com, 188/89 Prince Anwar Shah Road, Lake Gardens, 700045 Kolkata, India; \\ (iD) ananya@banglanatak.com (corresponding author) \\ 2 Indian Statistical Institute, Delhi Centre, B-2 Staff Quarters, 7, S. J. S. Sansanwal Marg, 110016 \\ New Delhi, India; (D) madhura@banglanatak.com \\ 3 Centre for Dance Research, Coventry University, Priory St, Coventry CV1 5FB, United Kingdom; \\ (iD) charlotte.waelde@coventry.ac.uk
}

\begin{abstract}
Can intellectual property and marketing strategies help bearer communities to make a sustainable living from their intangible heritage? This is the question that underpinned a British Academyfunded interdisciplinary research project that comprised researchers from the UK, France, and Italy, and an NGO from Kolkata. This contribution describes the development and implementation of heritage-sensitive intellectual property and marketing strategies (HIPAMS) with two communities in West Bengal - Chau dancers and Chau mask-makers who were at the heart of the project. Using methods including forum theatre and walking stories, the research team and the communities' highlighted challenges faced by the communities in making a sustainable living from their heritage skills and developed ways in which HIPAMS could be used by the communities to their advantage while retaining a focus on the importance of the heritage. The initial evaluation shows how significant these strategies can be for heritage communities, however small and incremental the advances made.
\end{abstract}

Keywords:

ethical approaches; intellectual property; Creative Economy; ICH and marketing.

\section{Introduction}

Cultural and creative enterprises based on intangible cultural heritage such as visual and performing arts and traditional crafts can be sources of livelihood and income for tradition bearers. The globalized world provides opportunities for reaching out to new audiences. As was noted in UNESCO's report 'Investing in Creativity', the global revenue of the creative industries is 2250 billion USD and the sector employs 30 million. $20 \%$ of those working in the sector are under 30 years and $45 \%$ are females (UNESCO, 2018). Recognizing the potential of the sector the United Nations declared 2021 as the International Year for Creative Economy for Sustainable Development.

Despite having a wide range of specialized institutions, India lacks a coherent policy and institutional framework for the development of the creative and cultural industries. There is no definition of 'creative industry' in India and so the concept does not feature in thinking about mainstream economic growth in the country, except in relation to a few regular exports of craft products. India does however have an extensive cultural asset base and a young workforce with technical skills capable of driving a sustainable and thriving creative economy.

Digital technology is emerging as an essential tool for professional development and ensuring a fair share of the benefits that it can bring for artists and craft makers. Digital technologies and social media provide affordable means of promotion, distribution, and sale of heritage products. The COVID-19 pandemic has disrupted traditional value chains

\section{How to cite}

Bhattacharya, A., Dutta, M., \& Waelde, C. (2021). Designing Heritage Sensitive IP and Marketing Strategies for ICH-Based Creative Economy. Culture. Society. Economy. Politics, 1(2), 72-87.

https://doi.org/10.2478/csep-2021-0012

ISSN (online) 2810-2010

https://website.sciendo.com/publication/culture-society-economy-politics/

http://www.facultateademanagement.ro/culture-sep/ 
and accelerated the use of digital tools to access culture as well as to buy and sell cultural products. The commercialization of artifacts and performances derived from intangible cultural heritage $(\mathrm{ICH})$ has been the subject of extensive academic and policy discussion because of the possible unintended outcomes that can arise from overcommercialization. These include the loss of value and meaning of the heritage, decontextualization or misappropriation of the heritage, or abuse of the embodied knowledge and skills underpinning the heritage (UNESCO, 2020, p. 104). There is however lack of guidance on how ICH may be commercialized in appropriate ways and within limits, and whether intellectual property rights-based tools could be used to avoid the harms associated with over-commercialization. The application of conventional intellectual property (IP) rights, such as copyright, patents, and design protection, is limited in the case of cultural services and products based on ICH as ICH is passed down through generations and changes and evolves as it is adapted to new contexts. However, IP tools can be useful where heritage-sensitive innovation results in performances and products that satisfy the criteria for protection by IP - such as a new choreography that bases itself in traditional dance steps; or new paintings that are developed from embodied ICH skills and knowledge.

In this paper we share experience from a research project funded by the British Academy, 'Celebrating local stewardship in a global market: community heritage, intellectual property protection and sustainable development in India'. This project involved an interdisciplinary team of experts from the UK, France, and Italy, and banglanatak dot com (www.banglanatak.com), a social enterprise working in India. The project team worked closely with four marginalized heritage communities from West Bengal with whom the work and outcomes were co-created. These include digital and intellectual property-based strategies and tools for the promotion of ICH-based artifacts and performances.

This paper describes how the project worked with two of the communities - Chau dancers from Purulia and Chau mask makers from Charida, both in West Bengal, India and how the project contributed to economic and social development and empowerment of these communities. The focus is on the heritage-sensitive marketing and intellectual property strategies co-created during the project - abbreviated to HIPAMS in the project (hipams.org).

\section{Heritage, IP, and marketing}

Commoditization and commercialization of ICH have been means for benefitting communities while retaining meaning and value (Lixinski, 2018). Tradition bearers earn from their heritage-based products and services through patronage, sales, and gifts (Seifpour \& Zandieh, 2019). However, concerns have been raised over misappropriation and misrepresentation of elements of ICH. Commercialization efforts by state or commercial agencies have been questioned because of the harm that could result for the bearer communities and their ICH (Akagawa \& Smith, 2009; 2018; Forsyth, 2012; Harding, 2018; Kirshenblatt-Gimblett, 2004). These activities are often referred to as over-commercialization - but there is a lack of practical guidance as to how the communities might address the harms caused.

Current academic theories have not yet focused on the relationship between heritage and the market, exploring how communities could plan for commercialization while protecting the value and meaning of the heritage and mitigating risks (Lixinski, 2018, 2020), nor on the problems of under-commercialization which may lead to the eventual disappearance of the ICH (Bortolotto, 2020; Rinallo, 2018).

The key idea that it is the tradition bearers and practitioners who should define their ICH and its value to them, and should be the ones to lead on its safeguarding and 
management, is well articulated in the Ethical Principles (2015) of UNESCO 2003 Convention. The Operational Directives (UNESCO, 2020, pp. 104, 173) mention using IP rights as a useful tool to ensure the sustainable development of $\mathrm{ICH}$, helping to protect against over-commercialization and misappropriation. There has been some academic research on the role of IP rights protection in safeguarding ICH (Farah \& Tremolada, 2015 , p. 218). Recent work has identified ways in which a range of different IP rights protection strategies could be used alongside other mechanisms, such as contracts and ethical guidelines, to help communities safeguard their ICH and benefit from it (Deacon \& Smeets, 2018; Janke, 2003; Lixinski, 2013; Ubertazzi, 2018). The World Intellectual Property Organization (WIPO) has, over several years, attempted to develop sui generis IP protection at the international level but this, to date, has not been successful (Drahos, 2014; Goswani \& Nandi, 2008). As regards marketing theory, the project drew on theories of authenticity from marketing and psychology literature applied to cultural heritage, as found in the works of Kreuzbauer and Keller (2017), Morhartetal (2015), Kolar and Zabkar (2010), Gilmore and Pine (2007) to understand the risks of commercialization and commodification.

Drawing on these backgrounds the project team theorized that an interdisciplinary approach combining ICH sensitive marketing with expert knowledge about IP could result in heritage sensitive commercialization strategies that had the potential to be enforceable - or at least recognized - in the global marketplace. By contrast, if commercialization strategies were developed without recourse to the theoretical and practical marketing and legal frameworks, the likelihood of their being sustainable over time would be limited.

\section{ICH and commercialization in India}

ICH-based creative and cultural industries are one of the largest income-generating sectors in India (IBEF 2021). The handicraft and textile sector is the second largest employment source after agriculture. As shown in a study on 'Enumeration of Craft Persons in 2013' there were 16.3 million craft workers in 2001 (MSE, 2013). India however lacks information on the number of people in the country who make a living from income based on ICH. However, the sector faces challenges from a lack of enforceable rights resulting in the inability to prevent third parties from imitating ICH products and misappropriating traditional knowledge, techniques, and forms. Conventional IP rights protection for individual creators does exist in India, including copyright and performer's rights. India's legal framework also provides protection for crafts through collective IP rights such as geographical indications. India has not yet developed sui generis IP protection at the national level for traditional knowledge but provides defensive protection through the Traditional Knowledge Digital Library (TKDL), to reduce erroneous patenting 1 .

However, and while globalization and the internet revolution have combined to make the world feel smaller and give easy access to information, for traditional rural heritage communities in India significant hurdles stand in their way of taking advantage of the benefits these advances have promised, including the ability to use IP rights when commercializing their ICH. These hurdles include fragmented value chains; the lack of entrepreneurial capacity, direct market outreach, education, literacy, marginalization, and the absence of a coherent ecosystem to educate, inform, and facilitate knowledge about IP tools that may be available when commercializing ICH. Since traditional cultural assets embody cultural, social, and historical value, as well as economic value, and are based on community knowledge and ownership, IP strategies need to be sensitive and

\footnotetext{
1 The International Institute for Environment and Development (Swiderska et al., 2009) has worked with communities in China, India, Kenya and Peru to develop tools such as community bio-cultural registers, marketing strategies and protocols that could be used to help protect rights over traditional agricultural knowledge, while recognizing existing models of community stewardship and regulation
} 
holistic. As noted, a range of IP tools exist including geographical indications, trademarks, copyright, and performers rights. However, from a practical perspective, the protection of ICH (called traditional cultural expressions in WIPO) through IP is challenging. Copyright and performers rights for instance are generally suited to contemporary works where the individual author and performer can be identified - ICH by contrast has been handed down through the generations and is generally considered to be vested in the bearer community. That said, both copyright and performers' rights can protect contemporary manifestations of ICH, such as a contemporary choreography based on traditional dance moves; copyright can protect the choreography and rights of the performer of the dance. Geographical indications, which act as indicators of origin, can be used by traditional communities where the relevant law recognizes the traditions on which the ICH is based such as those embodied by the Chau mask makers from Charida. A significant challenge however for the application of traditional IP laws is the practical ability to enforce infringements. For copyright and performers rights this is challenging for a range of reasons, not least of which is the cost of enforcement. For geographical indications, where enforcement can be in the hands of a Government agency, this may prove to be a more workable strategy, but one that will still face the complexity of the court system.

India, recognizing the importance of having a developed IP policy, adopted the National Intellectual Property Rights (IPR) Policy in 2016 under the Ministry of Industry and Commerce (CIPAM 2016). This marked India's commitment towards protecting and promoting IP to capitalize on the potential of India's knowledge economy. Its vision statement included art, culture, and traditional knowledge among the key knowledge resources for driving development and strengthening the competitive edge of the country. The policy document states:

While India has always been an innovative society, much of the intellectual property (IP) created remains unprotected both on account of lack of awareness and the perception that IP protection is either not required or that the process to obtain it is unnecessarily complicated. The rationale for the National IPR Policy lies in the need to create awareness about the importance of intellectual property rights (IPRs) as a marketable financial asset and economic tool.

The Department for Promotion of Industry and Internal Trade (DPIT) is responsible for implementing the policy. The department coordinates with the World Intellectual Property Organization (WIPO) which works together to strengthen the IP ecosystem through introducing appropriate legislation for protection, enforcement, and more generally the promotion of respect for IP.

\section{Purulia Chau dance}

Chau is an acrobatic martial art dance practice in the Chotonagpur Plateau region of eastern India. It is inscribed in the UNESCO Representative List of Intangible Cultural Heritage of Humanity (UNESCO, n.d.). There are three variations of Chau dance Saraikela, Mayurbhanj, and Purulia Chau, the names pertaining to the districts in three neighboring states of India, Jharkhand, Odisha, and West Bengal respectively. In Purulia Chau (www.puruliachau.com) the dancers wear large, colorful, ornate masks and costumes. In Mayurbhanj Chau the dancers do not wear a mask while the mask is smaller and simpler at Saraikela. Purulia Chau dance is characterized by somersaults and acrobatic movements.

There are three styles of Chau dance, as illustrated by Figures 1, 2, and 3. 


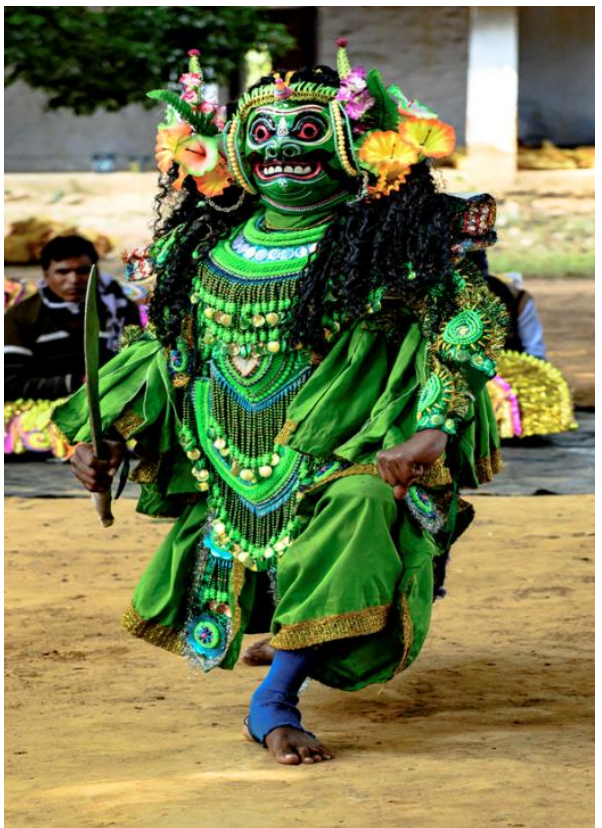

Figure 1. Purulia Chau 2019

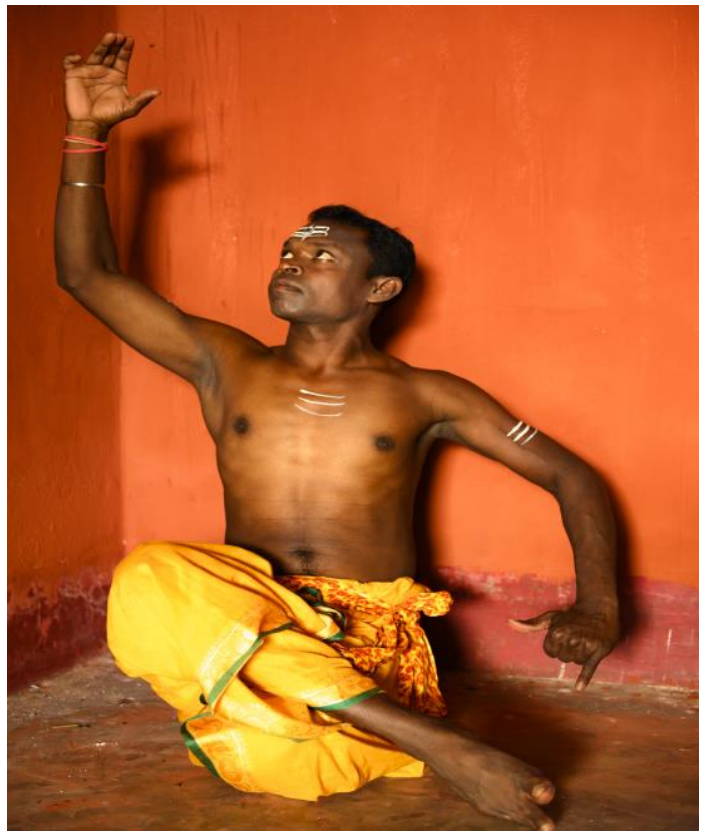

Figure 2. Mayurbhanj Chau 2019

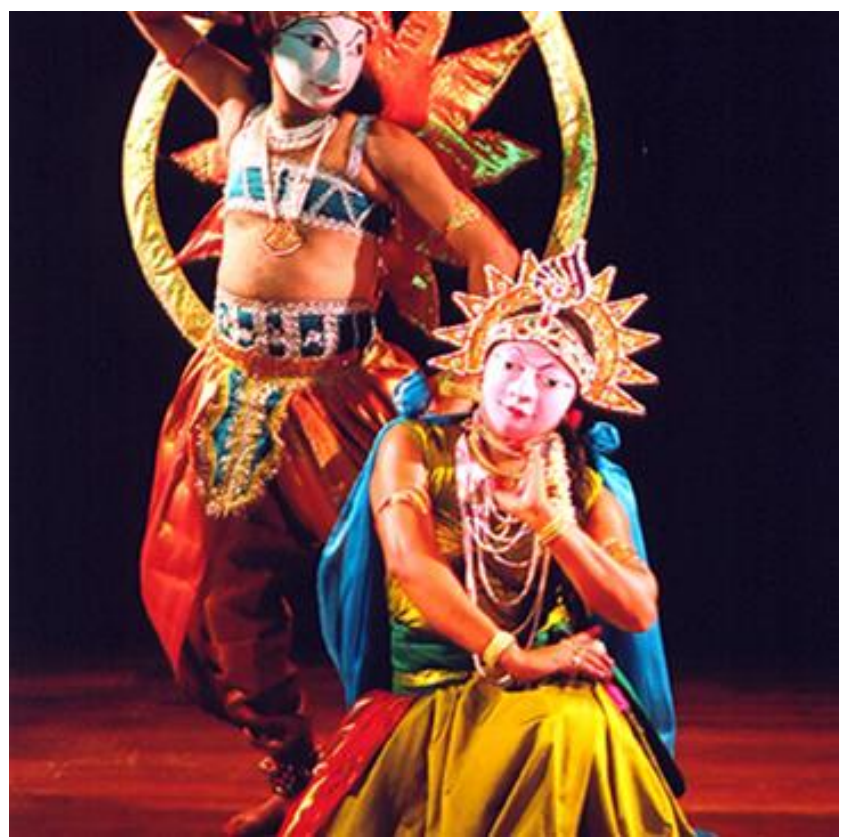

Figure 3. Saraikela Chau 2017

(Picture courtesy: https://www.sahapedia.org/stories-behind-the-masks)

There are ten to twelve dancers. They are accompanied by musicians playing drums like Dhamsa and Dhol, clarinets, and other traditional folk instruments. Folk singers intermittently present the storyline and dialogues through song. Stories of Chau dance are from epics, mythology, and also local folklore.

While Chau dance is popular across the district of Purulia, the mask-making community resides in a village called Charida. The tradition of making Chau masks started in Charida around 150 years back during the rule of King Madan Mohan Singh Deo of Baghmundi. Masks (Figure 4) are made by hand using paper mâché and clay and decorated with laces, trinkets, plastic straws, and beads. Purulia Chau dance is particularly associated with the Chait Parab during spring every year. During the elaborate ritual of Gajan (or 
Charak), devoted to Lord Shiva of the Hindu Trinity, Chau serves as a form of entertainment for the devotees who stay up all night as part of the festivities.

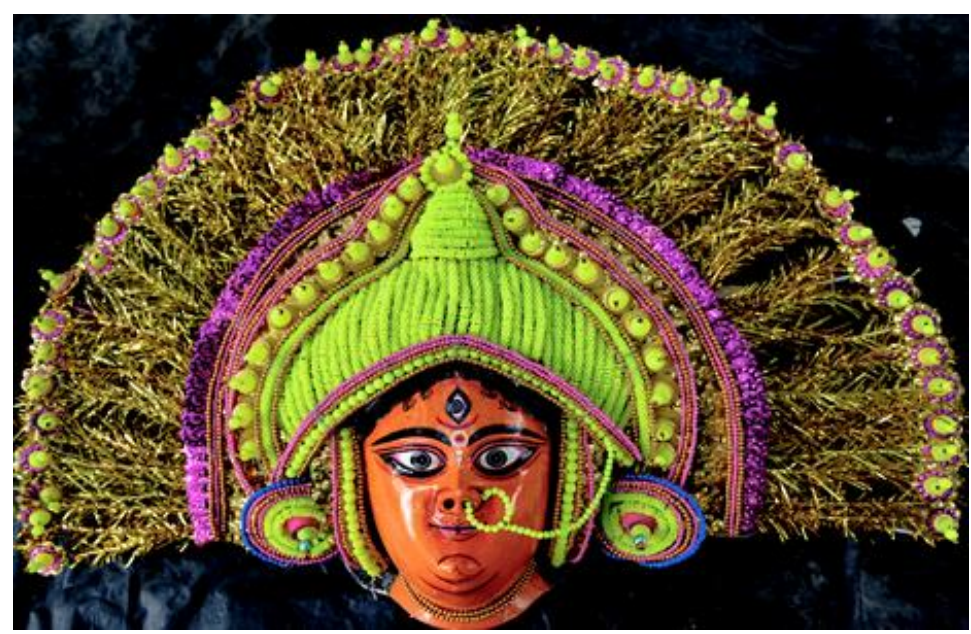

Figure 4. Traditional Chau mask made in Charida village 2019

\section{Art for Life initiative}

Banglanatak dot com, a social enterprise headquartered in Kolkata in West Bengal, started working for the revitalization of Chau dance as a sustainable livelihood option in 2005. Purulia is one of the poorest districts of India. It is semi-arid and has only one cropping season and villagers had to travel elsewhere for work. During non-farming seasons, families earned by binding tobacco leaves to make 'bidi' for smoking. Poverty and marginalization had led to dwindling opportunities for the community to nurture their heritage. During the local festivals, groups were quickly assembled for putting on performances but the dancers were seldom familiar with the story of the play they were enacting.

The Chau dance repertoire was endangered due to the absence of opportunities to learn the heritage from the masters and practice regularly. The younger dancers did not know the dance styles emulating movements of the birds and animals.

As part of Banglanatak dot com's, Art for Life (AFL) initiative started with support from the Eastern Zonal Cultural Centre, an autonomous organization under the Ministry of Culture, Government of India, skill transmission workshops were held at the villages under the leadership of the masters of the dance tradition. Lost styles were documented and an audiovisual publication sharing the history and meaning of Chau dance was recorded. Workshops were held in the villages to revive the lost styles, orient the young artists on heritage aspects such as the mythological and historical tales and the nuances of different styles. While Chau dance is traditionally performed for many hours, the Chau dancers were encouraged to develop productions of shorter duration of half an hour to an hour and were supported to perform in events and festivals across the state. Awareness of the dance form and improvements in performance quality led to an increase in demand among audiences.

As a result, the Chau dance groups started regular practice sessions and increased the number of their performances. Strong local market demand for traditional Chau dance was developed which benefits the Chau mask makers and traditional singers and musicians. Art residencies were organized to develop new productions based on works of Tagore and Shakespeare and collaborative work with contemporary dancers from India and abroad was encouraged. The Chau groups now regularly create new productions around historical and contemporary themes; a recent performance focuses on 'driving away the COVID-19 pandemic'. Before the pandemic, the Chau dance groups 
traveled nationally and internationally creating greater awareness of their vibrant dance form, performed in rural and urban festivals, and featured in Indian films such as Barfi! (2012), Lootera (2013), and Jagga Jasoos (2017).

With new stories and productions, the masks and costumes also differ from the traditional ones depicting gods and goddesses from mythology. Charida village in the Baghmundi block of Purulia districts is home to the community of 115 families of mask makers. The masks portray gods, goddesses, demons, animals, and birds. These mask makers traditionally made masks for Chau dance. Historically, mask making was considered a sub-industry of Chau dance, and the mask makers were not considered as skilled artists despite their unique craftwork. The mask makers made only a meager income from making and selling Chau dance masks during the performance season which lasted six months. During the rest of the year, they generally lived in poverty, earning an irregular income from laboring jobs.

Since the revival of Chau dance, each of the families in the community has enjoyed an almost two-fold increase in the numbers of masks they make, not only for Chau performances but also for new markets such as home decoration, leading to an increase in monthly income. The 'Chau Mask of Purulia' was registered as a geographical indication (GI) in 2018 (Figure 5), helping to increase visibility and origin identification of the mask makers and their masks in the market.

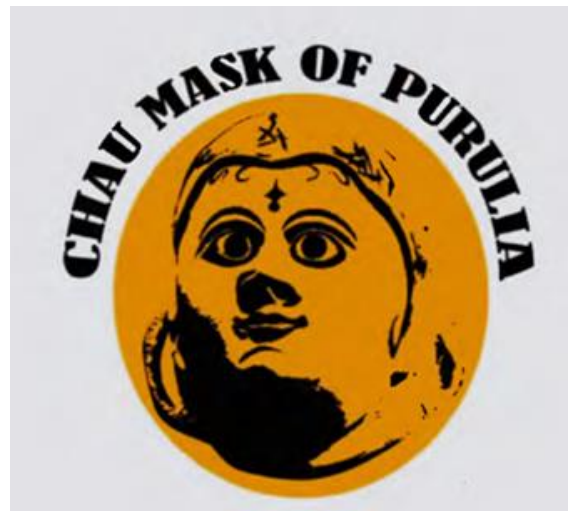

Figure 5. Geographical Indication: Chau Mask of Purulia

The AFL initiative also supported the development of the heritage bearers' village as cultural hubs and tourist destinations. Strategies included the setting up of folk art centers providing space for practice and promotion of the heritage art forms and developing annual heritage festival since 2010 providing opportunities for showcasing heritage performances and artifacts. Resource centers were established in the artist's villages with the support of the EU (2009-2011) and the State Government (2013-2019). These centers are living museums providing information on the history, origin, process, and styles of Chau dance and mask making, as well as providing opportunities to learn from the tradition bearers. There are Chau dance resource centers at Bamnia and Maldi village of Purulia and the Chau Mask Centre was established at Charida. In the last decade, the area has become popular for tourism. The mask-makers village festival in Charida was first held in 2013 to highlight the village as a tourist destination. The mask makers have established their workshops and galleries by the side of the road. Festivals including the Chau Jhumur Festival, organized in Bamnia since 2010, and at Maldi in 2019 , have added to the available attractions for tourists.

This investment in Chau dance form and mask making has transformed the artists into cultural professionals, enabled the development of grassroots cultural micro-enterprises and community-led cultural tourism, and transformed the lives of the communities through improved income opportunities. The AFL initiative has underpinned the revival 
of the ICH traditions in Purulia, strengthened the identity of artists and the communities, and generated pride among them. In so doing the initiative has contributed to achieving sustainable development goals (SDGs) by supporting the alleviation of poverty (SDG 1), augmenting work opportunities (SDG 8), and developing Purulia as one of the most popular weekend getaways for experiencing natural and cultural heritage (SDG 11).

\section{Gaps and challenges}

It was against this background that a team of interdisciplinary experts from Coventry University, banglanatak dot com, and Chau dancers and mask makers from the Purulia and Charida communities worked together in a research project supported by the British Academy to identify heritage sensitive intellectual property (IP) and marketing strategies (HIPAMS). The key idea was to explore how marketing and IP might help heritage bearer communities make a sustainable living from their heritage while remaining sensitive to their intangible heritage. Also central to the investigation was whether the use of IP strategies might help to mitigate against the harms of overcommercialization identified above. Ethically the research team considered it appropriate to work with the communities because the community members had already raised themselves out of abject poverty with the help of banglanatak dot com and the AFL project through the commercialization of their ICH. They had, in other words, already decided to make a living through the commercialization of their ICH. Having some experience in commercialization meant that they were at a stage where the introduction of marketing and IP strategies could be beneficial to their ICH businesses. Also central to working with the communities was that the strategies were all co-created between the research team and the community members, and this was facilitated through the expertise of banglanatak dot com's team of experts, and the use of arts and humanities methods suited to the expertise of the community members, including forum theatre and walking stories, as well as the more traditional questionnaires and semistructured interviews. Thirteen Chau dancers including one woman, and twelve Chau mask makers including two women, worked with the HIPAMS project team to develop strategies for augmenting the sustainability and viability of their ICH-based enterprises. The research team identified the need to provide a holistic theoretical framework for opening a space for discussions on innovation as a safeguarding measure and consider the artist ecosystem in relation to the market. During discussions with the Chau dancers, they stressed that the interrelationships between mask makers, dancers, and the Jhumur singers needed to be considered. Innovations in Chau masks may affect the dancers. Training for Jhumur singers needed to be carefully integrated into Chau productions. Such an approach would address emerging concerns around the lack of singers and musicians prompting the dancers to use recorded music and songs (Waelde et al., 2020). The artists also shared the challenges they faced as they engaged with event and festival organizers and crafts retailers. These included the lack of formal contracts; last-minute cancellation of events without any compensation; stages not suitable for the dance putting the artists at risk of injury; and the lack of attribution of the dancers in films and photographs were among the concerns raised.

As regards the mask makers, as noted, a GI had been registered for 'Chau mask of Purulia' in 2018. While an association of mask makers was in existence, it did not have a website or social media presence. There was a lack of collective marketing and promotion of Chau masks. While the mask-makers mentioned that some masks made elsewhere were wrongly marketed as Chau Masks of Purulia, they themselves were not very familiar with the use of the GI. The mask makers do not sign their masks.

\section{Digital tools to reach audiences and enhance the reputation}

Analysis of the availability of information about Chau dance and masks on the internet showed that there was a lack of content generated by the mask makers and the dancers. Much of the available information was posted by third parties. This posed the risk for the dancers and mask makers of inaccurate representation of their ICH and control of 
market access by third parties such as market intermediaries (such as distributors and resellers). The available content was mostly audio-visual videos and photographs of the vibrant dance and ornate masks. However, there was more information available about Mayurbhanj and Saraikela Chau than Purulia Chau. That the UNESCO nomination video had garnered over 156,968 views as of 18 March 2021 illustrated the public appetite for visual information about the ICH art forms. The multiple spellings of 'Chau' or 'Chhau' also created challenges as an internet search for one would not necessarily find the other, and so findings would necessarily be partial. Neither the dancers nor mask makers had considered using social media as a marketing tool; only a few had Facebook, Instagram accounts, or YouTube channels. It was observed by the research team that the Chau mask makers and Chau dancers did not promote their work collectively although the markets for dance performances and masks are inter-related owing to the shared cultural meanings.

As the dance and mask maker communities expressed the desire to address these issues (but not the absence of collective promotion of joint dancer/mask-maker endeavors), the project team, through tailored social media training, showed the artists how they could improve content and visibility of their art online. As part of the process, the artists reflected on their life and their love and pride for their art. Based on this they developed stories and created short videos which were shared via social media and on the project website. The artists were trained to use hashtag \#Purulia Chau for collective online promotion. By the end of the project, the artists were active online with more than half regularly using social media to share their work. $82 \%$ of the artists participating in the research now use Facebook and $65 \%$ of the mask makers have started using digital payment options like Paytm, Google pay, and Phone pay. The project team also worked with the artists to develop a common website (www.puruliachau.com) explaining the traditions, sharing the stories of the Chau dance drama, and providing information on the artists and their villages. The website also shares information about the UNESCO inscription and the GI registration.

During discussions with the mask makers, the project team noted how challenging it was for purchasers of the masks to transport these without them being damaged. Through discussion, the artists developed eco-friendly cardboard packaging for the masks. The GI was printed on labels on the packaging highlighting the place of origin of the masks (Figures 6 and 7). The labels also have a QR code that connects to the website where the story of the masked dance can be found.

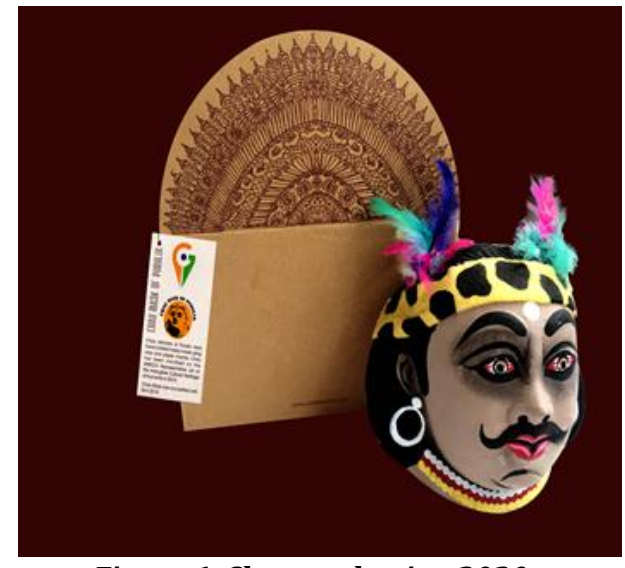

Figure 6. Chau packaging 2020

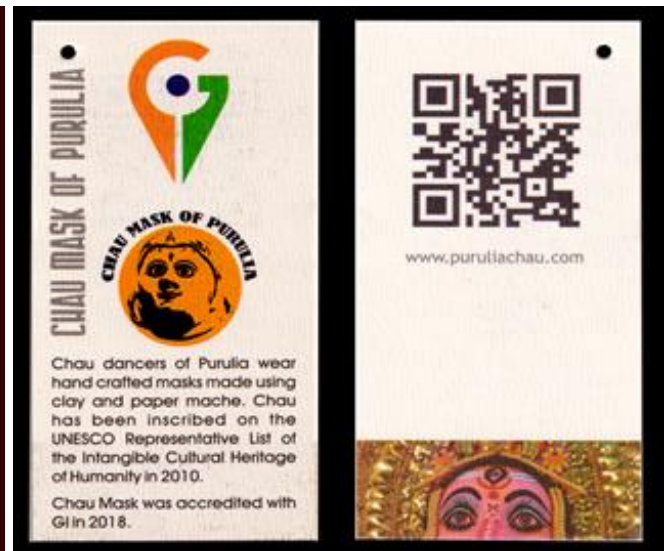

Figure 7. Chau packaging tag 2020

This innovation places the importance of the heritage at the heart of the marketing strategy and allows audiences to learn about the folklore and mythological tales and experience which are central to the dance. The mask makers reported on how buyers have expressed their appreciation as the packaging provided a fuller experience and 
conveyed the meaning and value of the heritage to them. Digital technology is thus supporting the bearers to promote their heritage tradition and strengthen branding in the market.

Digital storytelling and social media use has been important for the dancers and the mask makers during the pandemic and lockdown. The Chau mask makers increased their earnings from online contacts including purchasers from abroad while the dancers conducted online heritage education programs. Both the mask makers and dancers reported that audiences had contacted them after seeing their products and performance online - contacts which resulted in increased orders of masks and invitations to perform at events. As was noted by the artists during the evaluation, 'people can know about us' which they found reduced the need to convince purchasers to buy or to 'push' for sales. The artists also noted that they are now more aware of the importance of sharing information about their traditions as they reach out to new audiences.

\section{Promoting rights-based and ethical approaches}

When working with the Chau dance artists, the project team discovered that the dancers did not know about the existence of performers' rights in India. The dancers explained how they would be contracted by film companies to appear in films. Often, they were paid for their appearance, but they were not individually or collectively acknowledged or named in the credits. One of the young female dancers from the community, Moushumi Choudury from Maldi in Purulia, was featured in a film in a popular OTT channel. Though the story was inspired by her life and she performed the dances, her name was not mentioned in the credits. Training in intellectual property rights helped the artists to understand what rights the law provided for them, including being named as performers in the films, and as such enhance their negotiating power. The artists now seek the right proper acknowledgment for their performance in their contracts with the film companies.

Through discussion, it also emerged that copyright could be a useful tool for the Chau dancers and mask makers. Visitors would take photographs of the dancers and the mask makers and their work and circulate these on social media. While the artists welcomed the sharing of the images, they were seldom credited for their work, and there were times when the images could have been used commercially. The project team suggested that the dancers and mask makers ask that visitors use a Creative Commons(CC) license when circulating the images on social media to ask that they be given credit for their underlying performances and rights in their work. It was suggested that a CC-BY-NC license should be used which would allow circulation of the images so long as the dancer or mask maker was accredited (and their village) and so long as the use was for noncommercial purposes. Notice boards sharing information on the inclusion of Chau dance in UNESCO Representative List of ICH of Humanity and requesting the use of CC-BY-NC licenses when circulating images on social media are exhibited at the folk art centers, events, and festivals showcasing Chau dance and Chau masks. While such a strategy may be difficult to enforce should visitors not use the license, what it does is to start teaching both the artists and the visitors that the artists have rights in their creative works and that these rights should be respected. 


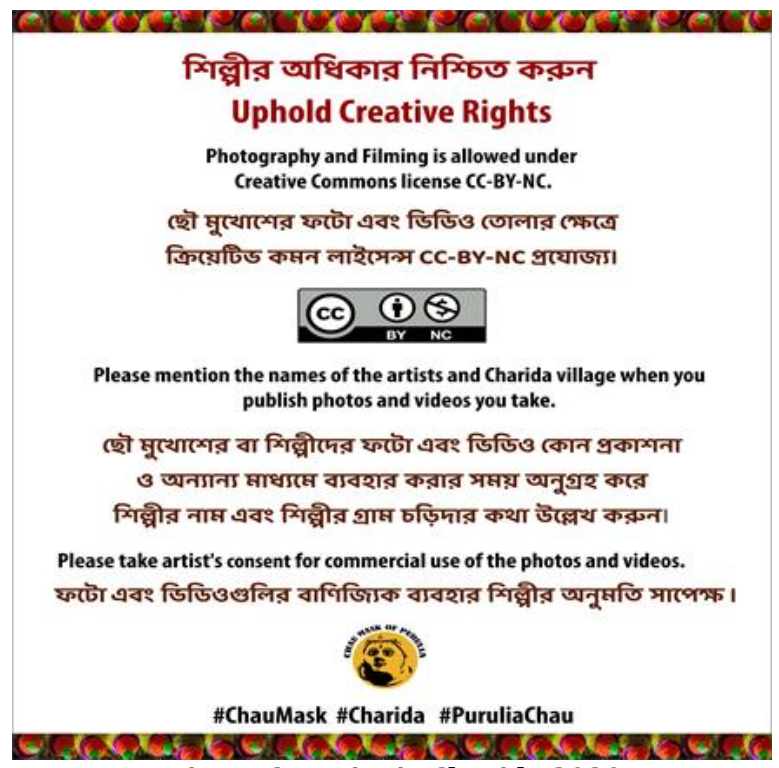

Figure 8. Notice in Charida 2020

The geographical indication (GI) is also proving to be important for the mask makers. The artists are now registering under the GI system and after training, are more aware of how the GI logo can be used to differentiate their products from those of mask makers outside the community. Also important is the potential to use the GI to attract buyers and increase the prices of the masks.

While the use of IP tools to underpin the marketing strategies developed in the project proved to be important, their limitations were fully acknowledged. As noted, the practical inability to enforce IP rights was an important factor leading to using them as promotional tools, rather than to defend rights. This lack of enforceability, together with the recognition that a number of the problems faced by the dancers did not have a legal solution, were among the factors that lead to the decision by the communities to develop ethical codes. These are brief documents that contain several statements setting out what the communities want from those who work within the marketplace. The statements are rooted in IP language, the UNESCO Intangible Heritage Convention's Ethical Principles (2015), and the general Human Rights framework. The Chau dance code: 'Treating Chau Dance artists fairly. Code of Ethics and Practical Guidelines for performance organizers, the media, and researchers state that the dancers would like the people with whom they work to understand the meaning of Chau Pala (productions), to respect their Chau heritage, and to be paid fairly for their performances. Those who organize performances can therefore help by respecting Chau dance heritage, employing musicians using traditional instruments, and Jhumur singers, attributing the dancers and acknowledging their contributions.

The mask makers' code contains similar sentiments, along with requests that their contributions should be acknowledged when their masks are used in Puja Pandals and in and on other works in public places, and that they should be attributed in books, films, and other products created about their work. While not legally enforceable, the ethical codes can be a useful negotiating tool for the dance and mask maker communities.

\section{Context-sensitive innovation}

A central strand of the project focused on the artists identifying the core heritage attributes or 'roots' of their dance and mask-making traditions. To help the communities visualize the roots of their heritage, and then how those roots then showed themselves in the fruits' of their innovations that were then commercialized, a 'roots and fruits' tool 
was developed. This enabled the dancers, for instance, to visualize the dance steps and stories that their heritage depended on, and then how that traditional embodied intangible heritage manifested itself in contemporary choreography, such as a new dance that was performed as part of the project, 'the dancer behind the mask'. There are also new Chau dance productions on the pandemic, and the rights of women to dance Chau. Senior Chau dancers are trying to revive the old songs and Palas (drama storyline) of Chau.

Though the pandemic led to a loss of income for the dancers owing to cancellation of events and festivals and closing of cultural spaces, their improved reputation through social media, acknowledgment, and innovation have helped the artist groups to get more remuneration. Mousumi Choudhury's Instagram account 'chau-mousumi' is a good example of an innovative social media strategy developed as a result of the training and focus on context-sensitive innovation.

Similarly for the mask makers, using the roots and fruits tool they can focus on what is important to them in the roots of their heritage, which can then be manifested in new and innovative ways in contemporary masks and in products that are made for the market. One such example is the mask that was made for the project by mask maker Chau Mask by Dharmendra Sutradhar as shown below in Figure 9, and which now illustrates the roots and fruits tool in the HIPAMS toolkit.

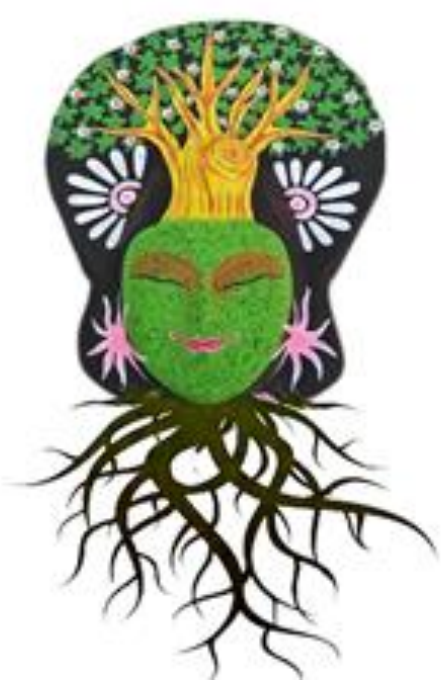

Figure 9. Mask by Dharmendra Sutradhar 2019

It was found that a 'fruit' may not use all the aspects identified as roots, (HIPAMS, 2020) and not all roots were necessarily used in all fruits. What the roots did was to enable the mask makers and dancers to identify their heritage skill repertoire, which they wished to maintain, and then to explore how new innovations can be developed.

The exposure to the internet has also made the communities aware of environmental issues and rights and some of their innovations are responding to these contexts. The mask makers are making eco-friendly masks using natural embellishments like tree bark, dry leaves, cereals, and seeds instead in place of plastic ornaments. They have also identified new market segments including home decoration and have made lampshades with masks, wall plates, and even masks sharing ideas from African masks. They identified the process of making the mask as the root element while fruits now vary from the traditional dance characters. They have developed half masks which can be used as protective gear during the pandemic such as this one by Falguni Sutradhar from Charida mask-makers village, Purulia who is pictured wearing his mask in 2020 (Figure 9). 


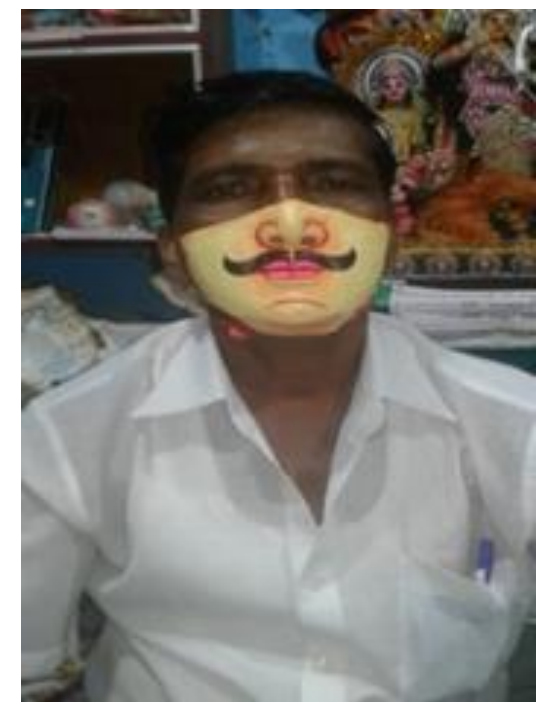

Figure 9. Falguni Sutradhar from Charida 2020

The mask makers have reported that these innovations are helping them to earn more.

\section{Conclusion}

This case study shows how the heritage-sensitive intellectual property and marketing strategies (HIPAMS) co-created with the Chau mask makers and dancers gave them the skills to innovate and market their art and performance and contributed to strengthening resilience. They are empowered to have greater control over how their art and performances are promoted and marketed. Their use of digital tools including websites, QR Codes, and social media offer a rich experience to audiences about their heritage. The artists have understood the importance of conveying the meaning and value of the heritage and not just offering a product or performance without its context. The ethical art codes notices to visitors in the festivals and resource centers have strengthened their negotiating power. Around 89\% of artists who participated in the research now think that taking permission from the artists for photographs and videos is important and are proactively urging proper attribution. Digital and IP-based tools have helped to give a voice to the marginalized and contributed to reducing inequality.

\section{References}

Akagawa, N., \& Smith, L. (Eds.). (2018). Safeguarding intangible heritage: practices and politics. Routledge.

Bortolotto, C. (2011). Patrimonio Immateriale e Autenticità: Una Relazione Indissolubile [Intangible Heritage and Authenticity: An Inseparable Relationship]. La Ricerca Folklorica, 64(October), 7-17. https://www.jstor.org/stable/23629701

Bortolotto, C. (2020). Intangible Cultural Heritage and the Market: The Embarrassment of Heritage Alienability, unpublished paper.

CIPAM. (2016). National Intellectual Property Rights Policy. Cell for IPR Promotion and Management, Ministry of Commerce \& Industries, Govt. of India. https://cipam.gov.in/index.php/about/national-ipr-policy/

Coombe, R. J., Ives, S., \& Huizenga, D. (2014). Geographical Indications: The Promise, Perils and Politics of Protecting Place-Based Products. In M. David \& D. Halbert (Eds.), Sage Handbook on Intellectual Property (pp. 207-223). Sage Publications.

Deacon, H., Rinallo, D., Basu, B., Bhattacharya, A., Nath, R., Patra, A., Taboroff, J., Ubertazzi, U., \& Waelde, C. (2022).Promoting sustainable development through intangible cultural heritage: The co-creation of heritage-sensitive intellectual property and marketing strategies (HIPAMS) with bearer communities. In Enhancing 
Intangible Cultural Heritage: Socio-economic contributions for ICH safeguarding, Fondazione Santagata, Italy. Forthcoming.

Deacon, H., \& Smeets, R. (2018). Intangible Heritage Safeguarding and Intellectual Property Protection in the Context of Implementing the UNESCO ICH Convention. In N. Akagawa \& L. Smith (Eds.), Safeguarding Intangible Heritage (pp. 36-53). Routledge.

Drahos, P. (2014). Intellectual property, indigenous people and their knowledge (No. 25). Cambridge University Press.

Farah, P. D., \& Tremolada, R. (2015). Conflict between intellectual property rights and human rights: A case study on intangible cultural heritage. Oregon Law Review, $94,125$.

Forsyth, M. (2012). Lifting the Lid on 'the Community': Who Has the Right to Control Access to Traditional Knowledge and Expressions of Culture?. International Journal of Cultural Property 19(1), 1-31. https://doi.org/10.1017/S0940739112000021

Gilmore, J. H., \& Pine, B. J. (2007). Authenticity: What consumers really want. Harvard Business Press.

Goswani, R., \& Nandi, K. (2008). Naming the Unnamed: Intellectual Property Rights of Women Artists from India. American University Journal of Gender, Social Policy \& the Law, 16(2), 257-281.

Harding, S. (2018). Contemporary Intangible Cultural Heritage and Right of Exclusion. In C. Waelde, C. Cummings, M. Pavis, \& H. Enright (Eds.), Research Handbook on Contemporary Intangible Cultural Heritage: Law and Heritage (pp. 78-104), Edward Elgar.

HIPAMS India Project. https://www.hipams.org/menu-3

HIPAMS. (2021a). Purulia Chau Case Study. www.hipams.org

HIPAMS. (2021b). The HIPAMS Toolkit. www.hipams.org

IBEF. (2021). Indian Handicraft Industry \& Exports. https://www.ibef.org/exports/handicrafts-industry-india.aspx

Janke, T. (2003). Minding culture: Case studies on intellectual property and traditional cultural expressions. WIPO.

Kirshenblatt-Gimblett, B. (2004). Intangible heritage as metacultural production. Museum International, 56(1-2), 52-65. https://doi.org/10.1111/muse.12070

Kolar, T., \& Zabkar, V. (2010). A consumer-based model of authenticity: An oxymoron or the foundation of cultural heritage marketing?. Tourism Management, 31(5), 652-664.

Kreuzbauer, R., \& Keller, J. (2017). The Authenticity of Cultural Products: A Psychological Perspective. Current Directions in Psychological Science, 26(5), 417 -421. https://doi.org/10.1177/0963721417702104

Lixinski, L. (2013). Intangible Cultural Heritage in International Law. Oxford University Press.

Lixinski, L. (2019). International Heritage Law for Communities: Exclusion and ReImagination. Oxford University Press.

Lixinski, L. (2020). Commercialising Traditional Culture: Promises and Pitfalls in the Convergence of Intellectual Property Law and Cultural Heritage Law. Annali italiani del diritto d'autore, della cultura e dello spettacolo (AIDA), forthcoming.

MSE. (2013). Enumeration of Crafts Persons in India. Madras School of Economics. https://www.mse.ac.in/wp-content/uploads/2016/09/Mono-25-.pdf

Morhart, F., Malär, L., Guèvremont, A., Girardin, F., \& Grohmann, B. (2015). Brand authenticity: An integrative framework and measurement scale. Journal of Consumer Psychology, 25(2), 200-218. https://doi.org/10.1016/i.jcps.2014.11.006

Purulia Chau. www.puruliachau.com

Rinallo, D. (2018). Map of ICH Food Commercial Valorisation Practices Across the Alpine Space. Alp Foodway Interreg Alpine Space Project Deliverable D.T2.1.1. https://www.alpine-space.eu/projects/alpfoodway/projectresults/wp2 map ich commercial valorisation practices.pdf 
Smith, L. \& Akagawa, N. (2009). Introduction. In L. Smith \& N. Akagawa (Eds.), Intangible Heritage, Routledge.

Swiderska, K., Pant, R., Argumedo, A., Song, Y., Mutta, D., Munyi, P., Herrera, H., \& Vedavathy, S. (2009). Protecting community rights over traditional knowledge: implications of customary laws and practices. Key findings and recommendations 2005-2009. IIED, London.

Ubertazzi, B. (2017). EU Geographical Indications and Intangible Cultural Heritage. International Review of Intellectual Property and Competition Law, 48, 1-26.

Ubertazzi, B. (2018). Italian intangible cultural heritage inscribed on the ICH UNESCO List: risks and opportunities. In P. Petrillo (Ed.), Unpublished book.

UNESCO. (2018). Investing in Creativity. https://en.unesco.org/creativity/sites/creativity/files/info-kit brochure-finalen-web.pdf

UNESCO Intangible Cultural Heritage (n.d.), Chhau Dance. https://ich.unesco.org/en/RL/chhau-dance-00337

UNESCO Office New Delhi, banglanatak dot com (India), Dept. of Culture and Tourism of West Bengal. (2011). Indian Heritage Passport Programme: on the cultural heritage of Purulia; a concept paper. UNESDOC Digital Library. https://unesdoc.unesco.org/ark:/48223/pf0000192865?1=null\&queryId=NEXPLORE-2c86e353-3447-44ac-a35d-a29f82ef8a21

UNESCO. (2015). Ethics and Intangible Cultural Heritage. https://ich.unesco.org/en/ethics-and-ich-00866

UNESCO. (2018). Investing in Creativity. https://en.unesco.org/creativity/publications/investing-creativity

UNESCO. (2020). Basic Texts of the 2003 Convention for the Safeguarding of the Intangible Cultural Heritage. https://ich.unesco.org/doc/src/2003 Convention Basic Texts- 2020 versionEN.pdf

Waelde, C., Deacon, H., Ramalingam, K., Rinallo, D., Ubertazzi, B., Taborof, J. (2020). Review of ContactBase's Art for Life Development Model amongBaul,Chau and Patachitracommunities. HIPAMS. www.hipmas.org

Zandieh, M., \& Seifpour, Z. (2020). Preserving traditional marketplaces as places of intangible heritage for tourism. Journal of Heritage Tourism, 15(1), 111-121. https://doi.org/10.1080/1743873X.2019.1604714

\begin{abstract}
Acknowledgments
The HIPAMS research team comprised Ananya Bhattacharya, Harriet Deacon, Rajat Nath, Anindita Patra, Diego Rinallo, June Taboroff, Benedetta Ubertazzi, and Charlotte Waelde. The authors would like to acknowledge the contributions of the Chau dance and Chau mask maker communities to the development of the HIPAMS project and the information reported in this chapter. The responsibility for the opinions expressed in this chapter remains with the authors.
\end{abstract}

\title{
Author biographies
}

Ananya Bhattacharya is the Co-founder and Director of banglanatak dot com, a social enterprise working for inclusive and sustainable development in India. Ananya is an electrical engineer from Jadavpur University, Kolkata (1989) and a Commonwealth Scholar with Masters in Sustainable Development from Staffordshire University, UK. Ananya has 15+ years of experience in the safeguarding of ICH and working with tradition bearer communities for their sustainable development through ICH. Art for Life initiative of her organization has led to socio-economic empowerment of 28,000 artists and craftspersons and rejuvenated 30+ ICH elements.

Madhura Dutta is a development sector professional and a freelance writer working in rural India for more than two decades, specializing in culture-based sustainable development. She has a Ph.D. from the School of Media and Cultural Studies, TISS, Mumbai, and MA degrees in Sustainable Development, Staffordshire University (UK) and in Sociology from the University of Calcutta. Madhura has extensive experience in the research and development of the craft economy. Madhura is currently a Director at Banglanatak dot com.

After a period as a commercial lawyer in private practice, Charlotte Waelde joined the University of Edinburgh Law School in 1995, becoming Professor of Intellectual Property Law there in 2008. In 2010 she moved to a chair in Intellectual Property Law at the University of Exeter and was Head 
of the Law School. Since 2016, she has been a Professor of Intellectual Property Law at C-DaRE. Prof Waelde's research has explored the interplay of law, technology, and culture in a series of interdisciplinary books and articles, including A World of Muscle, Bone \& Organs: Research and Scholarship in Dance (2018, Ellis, S., Blades, H. \& Waelde, C., eds.) and Research Handbook on Intellectual Property and Creative Industries (2018, Waelde, C. \& Brown, A., eds., Edward Elgar); Research Handbook on Contemporary Intangible Cultural Heritage Law and Heritage (2018, Waelde, C. Cummings, C. Pavis, M. Enright, H., eds., Edward Elgar).

(C) 2021 Faculty of Management (SNSPA), Author(s). This is an open-access article licensed under the Creative Commons Attribution-NonCommercial-NoDerivs License (http://creativecommons.org/licenses/by-ncnd/4.0/). 